\title{
Effect of internal and external EGR on cyclic variability and emissions of a spark ignition two-stroke cycle gasoline engine
}

\section{Amin Mahmoudzadeh Andwari ${ }^{1,2 *}$, Azhar Abdul Aziz ${ }^{2}$, Mohd Farid Muhamad Said $^{2}$, Vahid Esfahanian', Zulkarnain Abdul Latiff ${ }^{2}$ and Sharil Nizam Mohamad Said $^{3}$}

${ }^{1}$ Vehicle, Fuel and Environment Research Institute, School of Mechanical Engineering, College of Engineering, University of Tehran, Tehran 1439956191, Iran

${ }^{2}$ Automotive Development Center (ADC), Faculty of Mechanical Engineering Universiti Teknologi Malaysia (UTM), 81310 Johor Bahru, Malaysia

${ }^{3}$ Mechanical Section, UniKL, Malaysia Spanish Institute, Kulim, 09000, Kedah, Malaysia

*Corresponding Author, E-mail: amin.mahmoudzadeh@ut.ac.ir Tel: (+98) 2188020741

\begin{abstract}
Conventional two-stroke cycle engine suffers from typical drawbacks including lower combustion efficiency and excessive emissions of $\mathrm{uHC}$ and $\mathrm{CO}$ which are largely due to low in-cylinder average charge temperature at low load and speed regions of engine operating conditions. Utilising the hot burned Exhaust Gas Recirculation (EGR) technique can boost the in-cylinder average charge temperature of the engine. The influence of hot burned gases applied by means of both Internal EGR and External EGR strategies on the combustion stability and exhaust gas emission of a single-cylinder twostroke cycle engine running at low-load and mid-load of operating conditions was investigated experimentally along with simulation works using 1-D engine simulation code. The results indicated that both In-EGR and Ex-EGR improved the combustion stability (lower misfire cycle) and decreased the concentrations of uHC and CO emissions, specifically at low speed region; however, NOx concentration was increased. At Internal EGR setting of $30 \%$, the Coefficient of Variation for maximum in-cylinder pressure $\left(\mathrm{COV}_{\mathrm{Pmax}}\right)$ reached the minimum by 5.64 while when External EGR percentage was $25 \%$, COV Pmax approached about 6.67 at the mid-speed $(2000 \mathrm{rpm})$ of engine operating condition.
\end{abstract}

Keywords: Two-Stroke cycle engine; Internal EGR; External EGR; Cyclic Variability; Exhaust gas emissions.

\section{INTRODUCTION}

Concerns on sustainable energy supply and environmental protection are exerting rigorous demands on modern internal combustion engines (ICEs) to improve fuel efficiency. There is also a need to reduce carbon dioxide $\left(\mathrm{CO}_{2}\right)$ emissions to reduce global warming, and this calls for improvement in the design of ICEs [1-3]. Two-stroke cycle engines are well known for their significant advantages involving components, simple construction, lightweight, and less costly to manufacture. Two-stroke engines also have 
the potential to deliver almost twice the power density since there is one power stroke per revolution of the crank. The combination of lightweight and twice the power density makes two-stroke cycle engines feature a significant power-to-weight ratio and offer this advantage over the four-stroke engines [4-8]. For a long time, the objective of the different research works on two-stroke cycle engines optimisation was to eliminate two typical drawbacks consisting high emissions of uHC and poor fuel efficiency. The former leads to unstable engine operation (cycle-to-cycle variation) combined with incomplete combustion, especially at idle and light engine loads. The latter is fuel short circuit at medium and full engine loads [9-15]. However, due to the short-circuiting of the fuel before combustion, this has resulted in deterioration in the engine's overall performances, especially poor combustion efficiency and high white smoke emission problem [16-22]. This cyclic variation is associated with lower average charge temperature of the cylinder; i.e., at low speed and load since the energy per each combustion cycle is too low to sustain high temperature for the next combustion cycle without misfiring occurrence. In-cylinder gas temperature at exhaust port closure moment $\left(T_{e p c}\right)$ can be increased sufficiently with the employment of exhaust hot burned gases; such a way is known as exhaust gas recirculation (EGR) technique [23-29]. The amount of $T_{e p c}$ must be high to achieve a complete combustion at the end of the compression stroke by means of spark plug ignition [30-36]. Basically, the major effects of EGR utilisation can be defined as: Charge-Heating Effect, Dilution Effect, Heat Capacity Effect and Chemical Effect [37-43]. Combustion burned gases inside of the combustion chamber can be retained in the combustion chamber by means of exhaust port area restriction. This strategy of burned gas utilisation is known as internal EGR (In-EGR). Likewise, a fraction of exhaust gas leaving the exhaust can be brought and rerouted back into the engine intake by also using a valve and this technique is called external-EGR or Ex-EGR [44-47]. This study aims to investigate the influence of both In-EGR and Ex-EGR on the combustion stability (cyclic variability) and exhaust emissions of a spark ignition single-cylinder two-stroke cycle engine by means of a 1-D simulation code along with experimental works.

\section{METHODS AND MATERIALS}

\section{Experimental Set-Up and Instrumentation}

A single cylinder two-stroke, naturally aspirated and liquid-cooled engine was used in conjunction with a comprehensive test bed facility for the experimental work. The reference for the engine specification is given in Table 1. The schematic view of the experimental set-up is presented in Figure 1, which illustrates the engine-dynamometer, the In-EGR and Ex-EGR mechanisms and the other instrumentations. Here, the In-EGR and Ex-EGR mechanisms are shown, which are basically valves placed after the exhaust outlet and are manually controlled. A gate type valve (diameter $25 \mathrm{~mm}$ ) fitted onto the EGR line adjusted the quantity of the exhaust gas to be rerouted back into the engine intake. The EGR line was insulated to minimise the heat losses to the environment. The valve and the feedback line are called Ex-EGR strategy of this engine set-up. Right after the exit of the exhaust port, there is a ball-type valve (38 $\mathrm{mm}$ diameter) designated as InEGR strategies. This valve regulated the outgoing hot burned gases so that a small fraction of residual combustion gases remained in the cylinder at the end of the exhaust stroke and mixed with the incoming cylinder charge. 
Table1. Experimental engine specifications.

\begin{tabular}{ll}
\hline Engine Type & Single Cylinder 2-Stroke \\
\hline Bore $\times$ Stroke & $59 \times 54.5(\mathrm{~mm})$ \\
Displacement & $149\left(\mathrm{~cm}^{3}\right)$ \\
Scavenging Type & Loop Scavenging \\
Scavenging Timing & $117.5 \mathrm{CAD}$ a/bTDC \\
Exhaust Timing & $82.5 \mathrm{CAD}$ /bTDC \\
Exhaust System & Expansion Chamber \\
Compression Ratio & $8.5: 1$ \\
Cooling System & Liquid Cooled \\
Fuel Supply System & Port Fuel Injection \\
\hline
\end{tabular}

Table 2. Engine operating conditions in simulation at idle and low speeds.

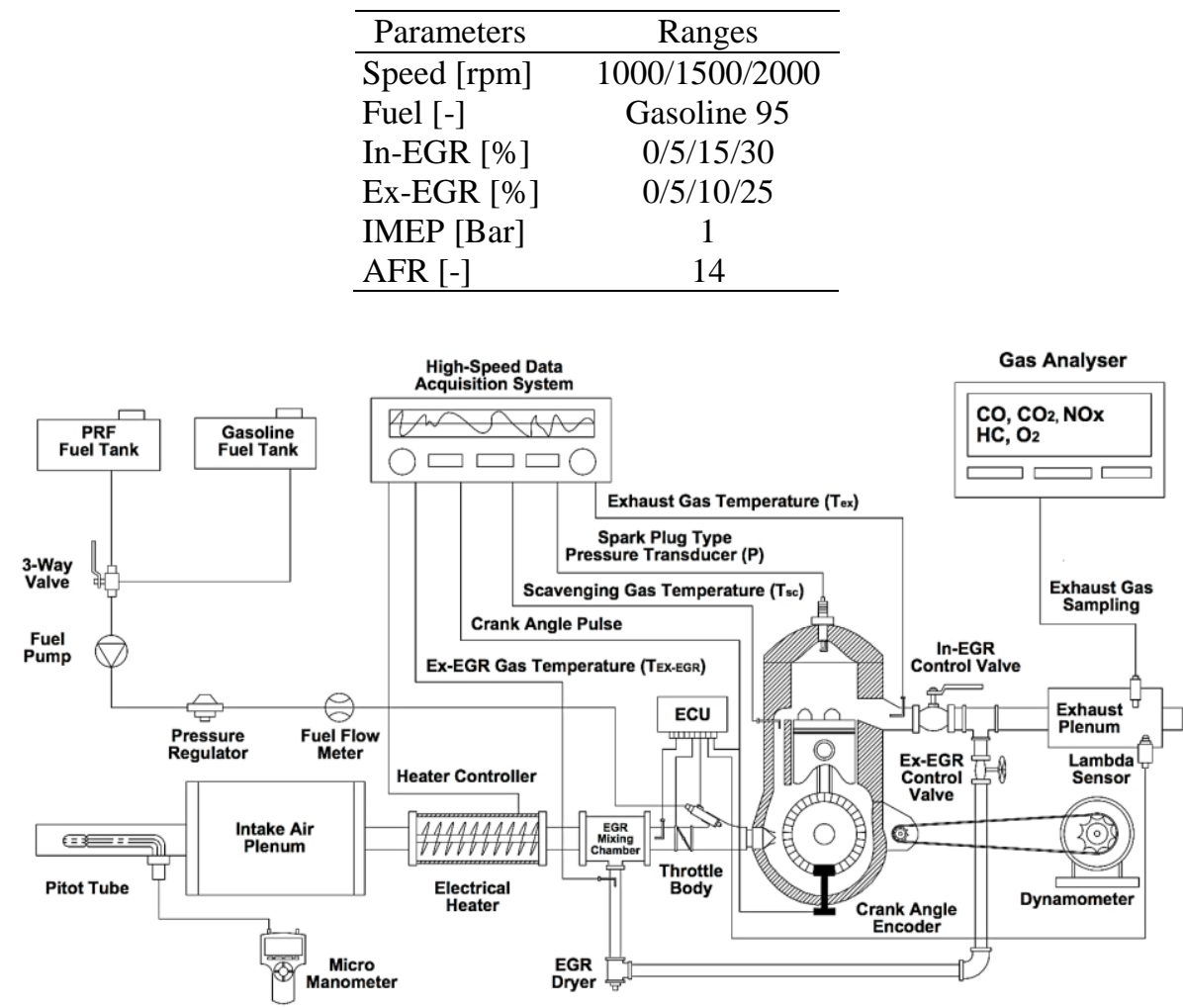

Figure 1. Schematic view of experimental set-up.

\section{Engine Simulation}

The reference engine was modelled using a 1-D engine simulation code wherein the emission was using the engine's geometrical inputs such as intake and exhaust runner, piping modelling, detailed specifications of combustion chamber and cylinder head shape, exhaust, and intake port timing. The graphical representation of the engine is as shown in Figure 2. The graphical 1-D code simulated representation for the engine is illustrated in Figure 2 based on the operating condition variables as presented in Table 2. In order to calculate the scavenging efficiency to estimate the percentage of In-EGR and Ex-EGR, it was presumed that scavenging process followed the idealised Isothermal Perfect-Mixing model [48-51]. Through the simulation procedures, engine was run in 
conjunction with different percentages of In-EGR and Ex-EGR in order to examine the combustion stability and the engine exhaust emissions output. Subsequently, three engine speeds were considered including 1000, 1500, and $2000 \mathrm{rpm}$ representing idling speed, low-speed and mid-speed engine operating conditions, respectively. Afterwards, the improvements in combustion stability and exhaust gas emissions due to utilisation of both In-EGR and Ex-EGR are presented in next two sections, which include the simulation and experimental results.

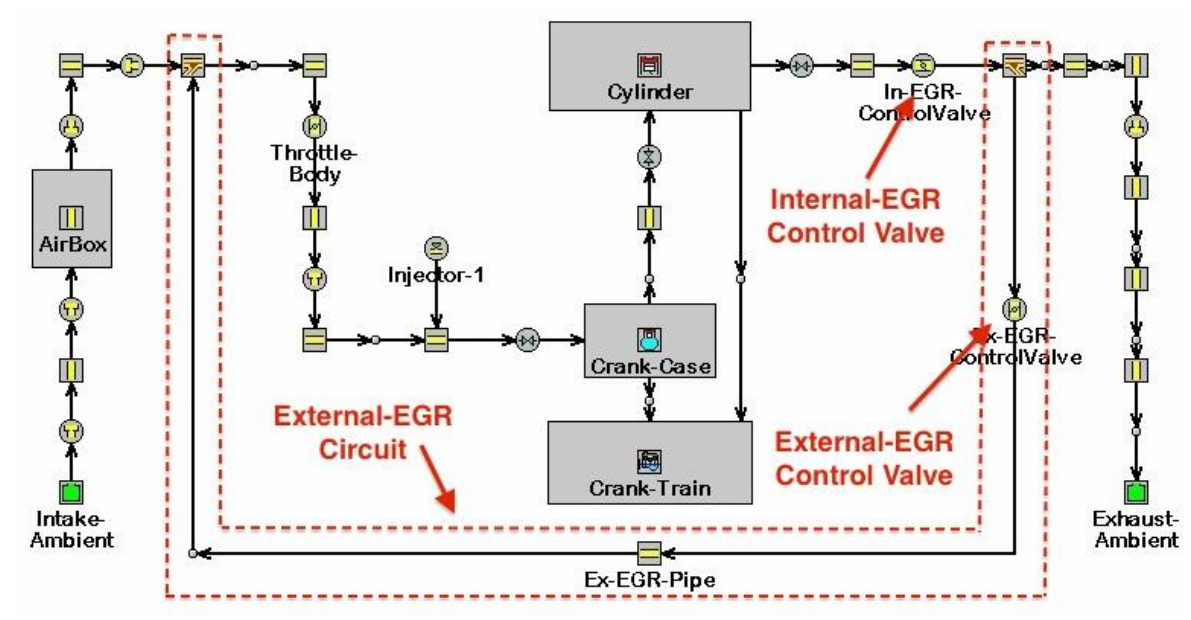

Figure 2. Engine 1-D simulation representation.

\section{RESULTS AND DISCUSSION}

\section{Combustion Stability at Idling, Low and Mid-Speed}

In order to determine the behaviour of the engine's combustion stability, maximum incylinder pressure $\left(\mathrm{P}_{\max }\right)$ as pressure-related parameters was taken into consideration while the In-EGR and Ex-EGR rates were varied. This was performed for 200 consecutive engine cycles. For each of the test point, the coefficient of variation of $\mathrm{P}_{\max }$ (i.e. $\mathrm{COV}_{\mathrm{Pmax}}$ ) was calculated to evaluate the engine combustion stability (cyclic variability) trend. Table 3 represents the engine operating condition at the designated engine speeds showing the setting preference for the In-EGR and Ext-EGR performed in experimental works.

Table 3. Engine operating conditions in experimental at idle, low and mid speeds.

\begin{tabular}{ccc}
\hline Speed [rpm] & In-EGR [\%] & Ex-EGR [\%] \\
\hline 1000 & 20 & 12 \\
1500 & 14 & 7 \\
2000 & 10 & 4 \\
\hline
\end{tabular}

Figure 3(a) illustrates the influence of In-EGR on the cyclic variability of $P_{\max }$ when the engine was at the idle speed of $1000 \mathrm{rpm}$. Here, $\mathrm{COV}_{\text {Pmax }}$ decreased when the percentage of In-EGR was increased. The fluctuation of $P_{\max }$ will be finally suppressed when In-EGR was at $30 \%$ setting, i.e. $\mathrm{COV}_{\mathrm{Pmax}}$ of 6.8. Figure 3(b) shows the influence of Ex-EGR on the cyclic variation of $P_{\max }$ at $1000 \mathrm{rpm}$. When the opening of the Ex-EGR was increased, cyclic variation of $\mathrm{P}_{\max }$ reduced. The fluctuation of $\mathrm{P}_{\max }$ was controlled 
when the Ex-EGR setting was $25 \%$ and COV $\operatorname{Pmax}$ was 7.55. The overall effect of both InEGR and Ex-EGR on the cycle-to-cycle variation of $\mathrm{P}_{\max }$ at idle-speed is explained in Figure 3(e). The higher the In/Ex-EGR percentage applied, the lower the cyclic variability of $P_{\max }$. The curves in the figure imply that in general when the In-EGR is applied, the cyclic variation of $\mathrm{P}_{\max }$ is lower than that of the Ex-EGR. As for Figure 3(c), the influence of In-EGR utilisation on cyclic variation of $P_{\max }$, at mid-speed $(2000 \mathrm{rpm})$ is shown. Table 2 shows the parameter settings employed for this simulation test.

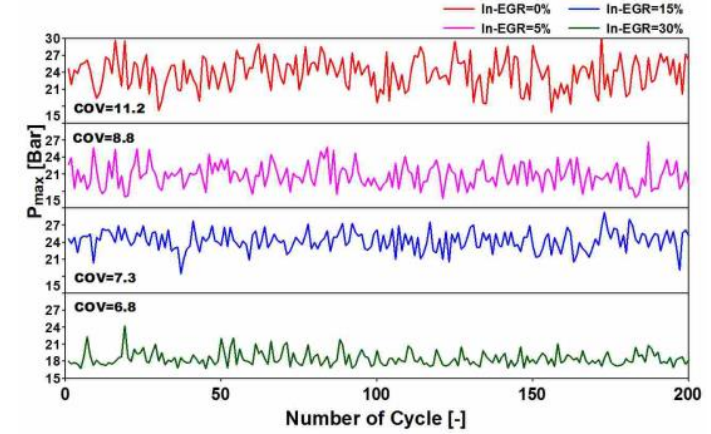

(a). $C_{\text {Pmax }}$ Vs. In-EGR at $1000 \mathrm{rpm}$

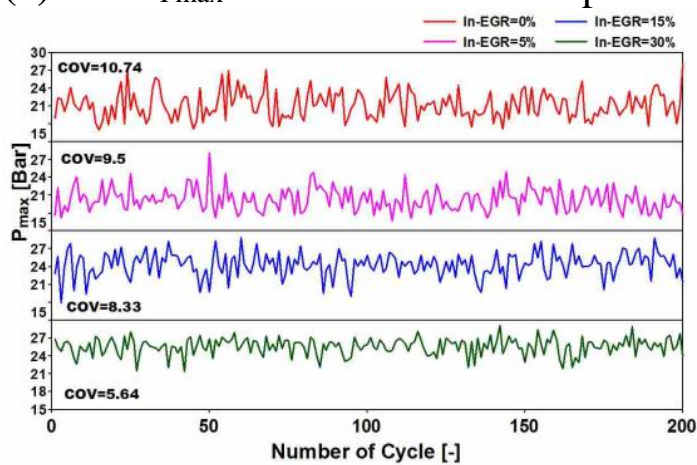

(c). $\mathrm{COV}_{\mathrm{Pmax}}$ vs. In-EGR at $2000 \mathrm{rpm}$

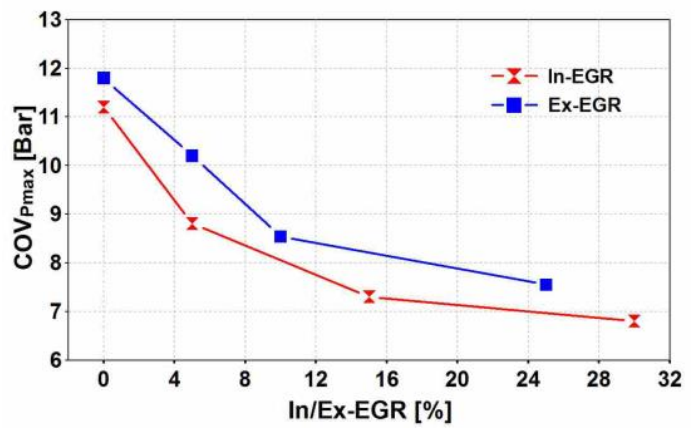

(e). $\mathrm{COV}_{\mathrm{Pmax}}$ variations at $1000 \mathrm{rpm}$

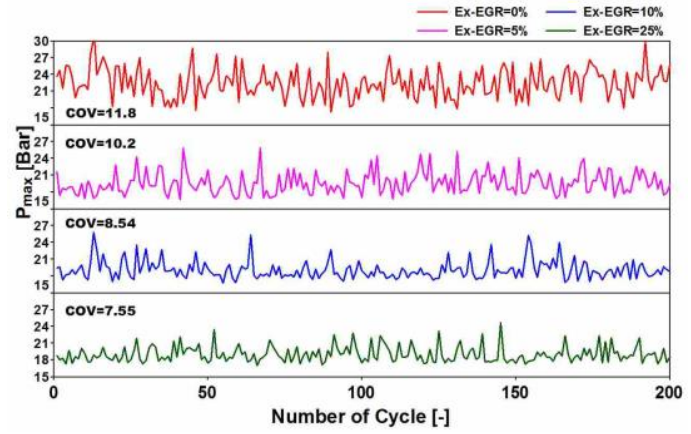

(b). $\mathrm{COV}_{\text {Pmax vs. Ex-EGR at } 1000 \mathrm{rpm}}$

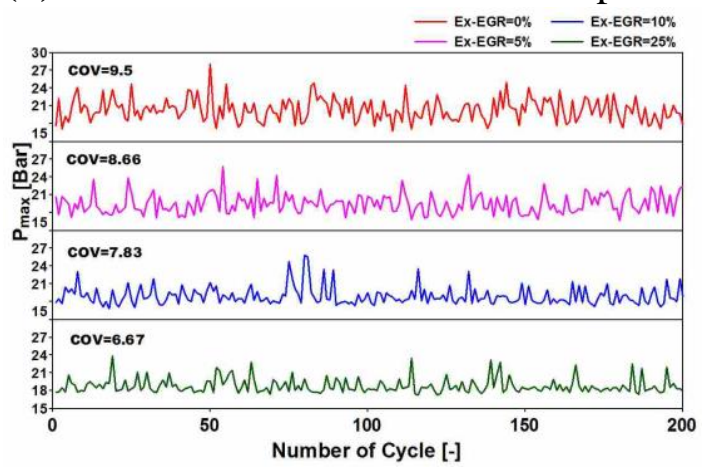

(d). $\mathrm{COV}_{\mathrm{Pmax}}$ vs. Ex-EGR at $2000 \mathrm{rpm}$

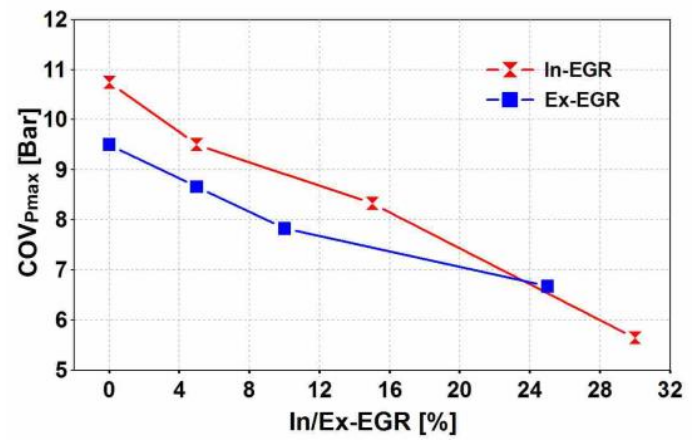

(f). $\mathrm{COV}_{\mathrm{Pmax}}$ variations at $2000 \mathrm{rpm}$

Figure 3. Influence of In/Ex-EGR on $\mathrm{COV}_{\mathrm{Pmax}}$ at Idling and low speed in simulation

When the concentration of In-EGR was increased, the cyclic variation of $\mathrm{P}_{\max }$ was noted to improve. At In-EGR setting of $30 \%$, the $\mathrm{COV}_{\text {Pmax }}$ has reached the minimum by 5.64. Similarly, the influence of Ex-EGR on the engine cyclic variation of $P_{\max }$ is illustrated in Figure 3(d). The pattern of the curves proved that the utilisation of Ex-EGR decreased the magnitude of $\mathrm{COV}_{\mathrm{Pmax}}$ and this indicated that the cyclic variation of $\mathrm{P}_{\max }$ has improved. As for Figure 3(f), the variation of COV Pmax due to In-EGR and Ex-EGR is presented. In general, it can be deduced that the higher the concentration of Ex-EGR, 
the lower the cyclic variation of $\mathrm{P}_{\max }$. Consequently, it was conceived that the cyclic variability was more likely to be influenced by variation of In-EGR rather than Ex-EGR when the engine was run at the idling speed, while the Ex-EGR was more prominent at mid-speed region.

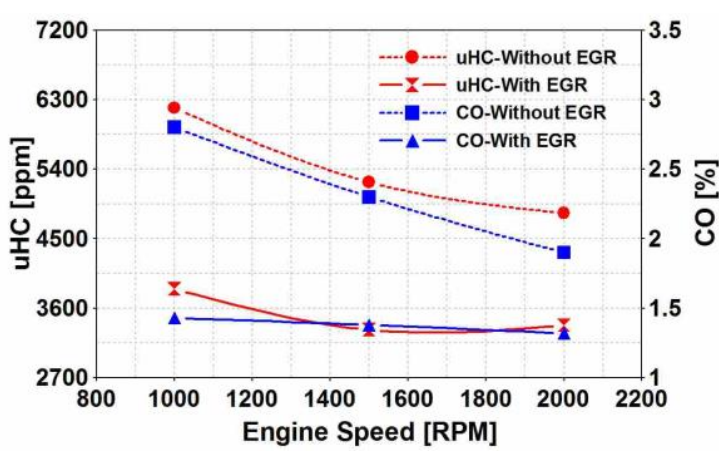

(a). uHC and CO vs. EGR (experimental)

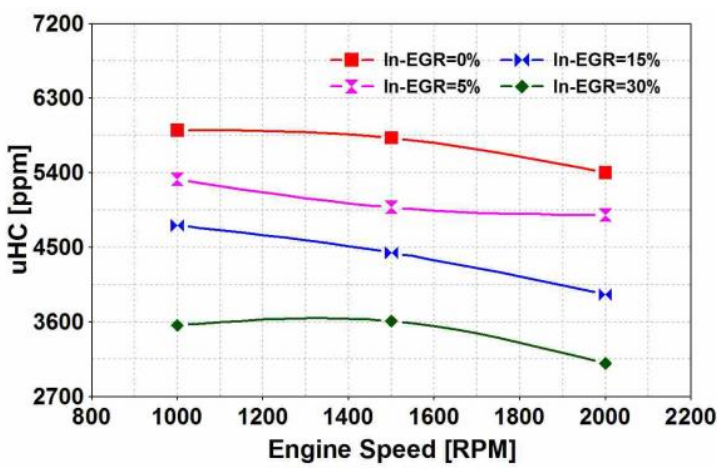

(c). uHC vs. In-EGR (simulation)

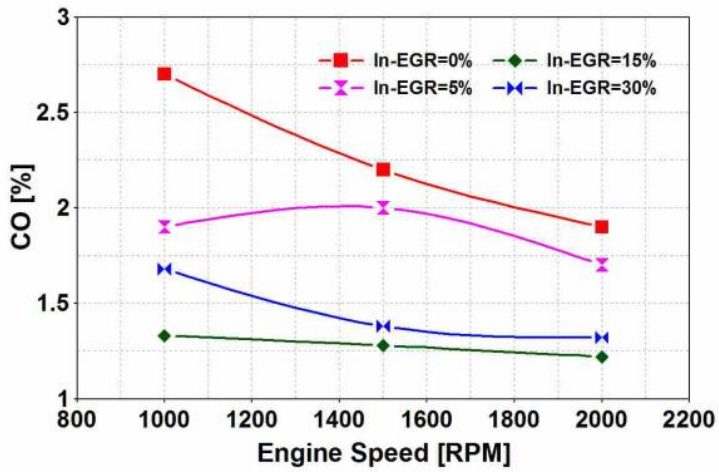

(e). CO vs. In-EGR (simulation)

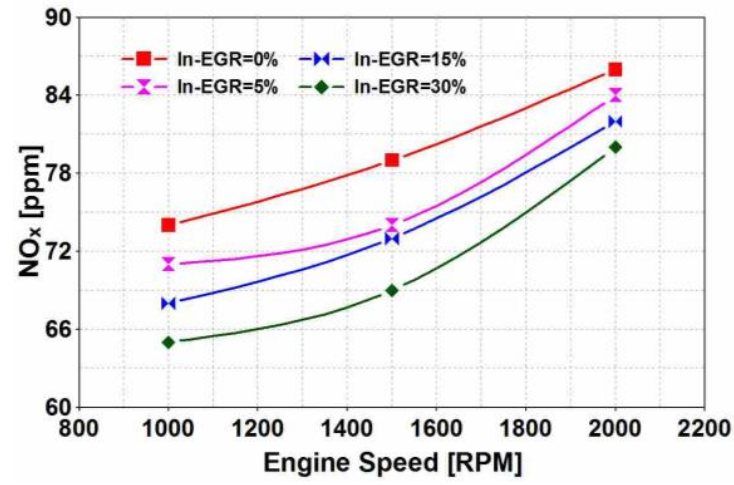

(g). NOx vs. In-EGR (simulation)

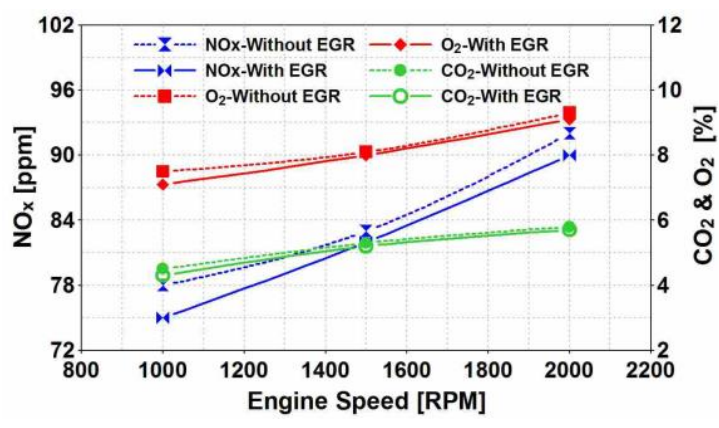

(b). $\mathrm{NOx}, \mathrm{CO}_{2}, \mathrm{O}_{2}$ vs. EGR (experimental)

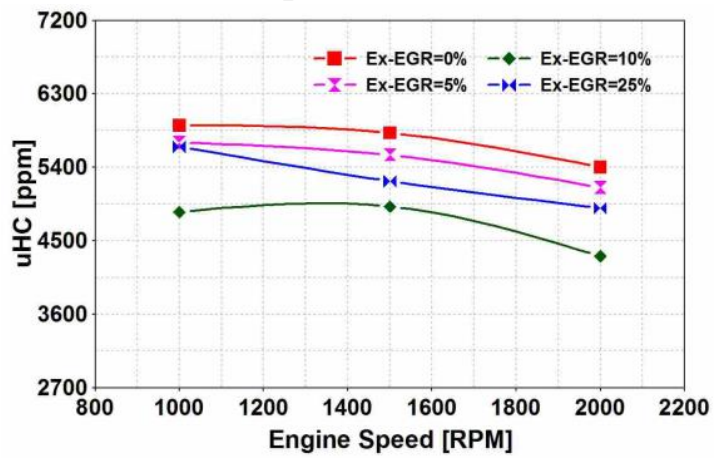

(d). uHC vs. Ex-EGR (simulation)

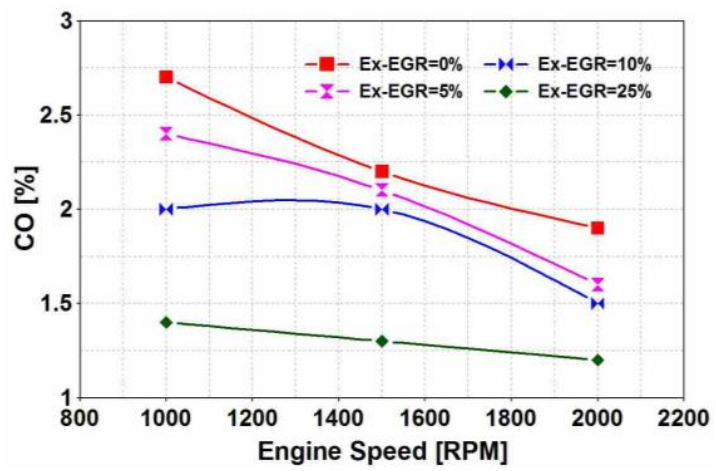

(f). CO vs. Ex-EGR (simulation)

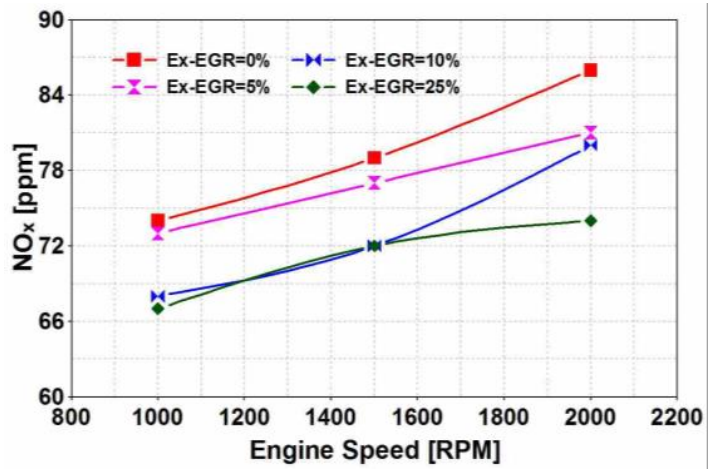

(h). NOx vs. Ex-EGR (simulation) 
Figure 4. Influence of In/Ex-EGR on emissions at idling and low/mid-speed conditions.

\section{Emissions Variations at Idling, Low and Mid-Speed}

In order to examine the exhaust gas emissions of the engine due to the variation of $\mathrm{In} / \mathrm{Ex}-$ EGR rates, the engine was run on 1-D engine simulation code at the three engine speeds as mentioned in Table 2. Figure 4 represents the overall operating condition of the engine in the simulation works regarding several concentrations of In-EGR and Ex-EGR for exhaust gas emissions analysis. Meanwhile, the variation in concentration of $\mathrm{uHC}, \mathrm{CO}$, $\mathrm{NOx}, \mathrm{CO}_{2}$, and $\mathrm{O}_{2}$ emissions in relation to In-EGR and Ex-EGR changes at experimental results are illustrated in Figure 4(a) and Figure 4(b) respectively. As for the experimental work, the exhaust gas concentrations were assessed under two separate conditions. First was without EGR and second was with EGR application as explained in Table 3. Once the incomplete combustion cycles (i.e. misfire cycle) were eliminated by using In/ExEGR, the exhaust constituents such as uHC and CO were altered. Figure 4(a) illustrates that the concentration of these constituents significantly decreased at all speeds. However, the improvements in $\mathrm{NOx}, \mathrm{CO}_{2}$, and $\mathrm{O}_{2}$ concentration were observed to be slight as shown in Figure 4(b). Moreover, in the simulation works, the variation in concentration of uHC in relation to In-EGR and Ex-EGR changes is illustrated in Figure 4(c) and Figure 4(d), respectively. As a whole, both In-EGR and Ex-EGR improved uHC emission output of the engine regardless of the engine speed. As the percentage of both In-EGR and Ex-EGR was increased, the concentration of uHC decreased accordingly. The higher the percentage of the In/Ex-EGR, the lower is the uHC emission. Comparing the curves of the figure, it can be concluded that the concentration of uHC emission was more influenced by In-EGR rather than Ex-EGR.

The concentration of $\mathrm{CO}$ emission in conjunction with In-EGR and Ex-EGR varied with respect to the three speeds as illustrated in Figure 4(e) and Figure 4(f), respectively. As can be seen in the figures, the concentration of $\mathrm{CO}$ emission decreased when the percentage of both In-EGR and Ex-EGR was increased. In general, it can be deduced that the $\mathrm{CO}$ emission has the same sensitivity to the variation of both In-EGR and Ex-EGR. The trend depicted by the curves in both figures proved that the emission of $\mathrm{CO}$ was less sensitive to the variation of both In-EGR and Ex-EGR when the engine speed was at $2000 \mathrm{rpm}$ (mid-speed) because the curves were converged at $2000 \mathrm{rpm}$ while they were diverged at $1000 \mathrm{rpm}$. In Figure 4(g) and Figure 4(h), the influence of both InEGR and Ex-EGR on the concentration of NOx emission is demonstrated. respectively. In general, the utilisation of both In-EGR and Ex-EGR decreased the NOx emission accordingly. The rate of NOx reduction in the case of In- EGR application followed a regular pattern; however, the rate of NOx reduction in the case of Ex-EGR did not, meaning that when the percentage of Ex-EGR was increased from 10 to 25, the concentration of NOx did not decrease considerably, in particular at $1000 \mathrm{rpm}$ and 1500 rpm. Furthermore, the NOx reduction at Ex-EGR setting of 5\% was more remarkable when the speed was at $2000 \mathrm{rpm}$. It is worth noting that even though uHC and $\mathrm{CO}$ were decreased (as the speed was increased), the concentration of NOx was raised when the engine speed increased. As such, it can be said that higher NOx concentration is attributed to higher combustion temperature developed in the combustion chamber.

\section{CONCLUSIONS}

A simulation and experimental investigation were conducted on a spark ignition single cylinder two-stroke cycle engine operated at constant load and three different speeds. Cyclic variability and emission characteristics of the engine were investigated in 
accordance with the variations of In-EGR and Ex-EGR. It was deduced that the emission characteristics of the engine in terms of $\mathrm{uHC}, \mathrm{CO}, \mathrm{NOx}, \mathrm{CO}_{2}$ and $\mathrm{O}_{2}$ and also the engine combustion cyclic variability were strongly influenced by In/Ex-EGR rates. In general, the results can be summarised as follows:

- Experimental results are in a good agreement with those of the simulation work wherein it can be deduced that the In/Ex-EGR regulated the engine emissions as well as its combustion variability.

- Both In-EGR and Ex-EGR mitigated uHC and CO emission quite remarkably but at the expense of NOx concentration having to be increased which was attributed to higher combustion temperature developed in the combustion chamber.

- The cyclic variability was more likely to be influenced by variation of In-EGR rather than Ex-EGR when the engine was run at idling speed, while the Ex-EGR was more prominent at the mid-speed region.

- The concentration of uHC emission was more influenced by In-EGR rather than Ex-EGR.

- The emission of CO was less sensitive to the variation of both In-EGR and ExEGR when the engine speed was at $2000 \mathrm{rpm}$ (mid-speed).

\section{ACKNOWLEDGMENTS}

The authors would like to acknowledge Universiti Teknologi Malaysia (UTM) for the financial support in funding this research project (Project No: 03-01-06SF1370).

\section{REFERENCES}

[1] Blair GP, Committee SPASP. Advances in two-stroke cycle engine technology. Society of Automotive Engineers; 1989.

[2] Heywood JB, Sher E, Engineers SoA. The two-stroke cycle engine: its development, operation, and design. Taylor \& Francis; 1999.

[3] Hosseini SE, Mahmoudzadeh Andwari A, Wahid MA, Bagheri G. A review on green energy potentials in Iran. Renewable and Sustainable Energy Reviews. 2013;27:533-45.

[4] Duret P. A new generation of engine combustion processes for the future?: Proceedings of the International Congress, Held in Rueil-Malmaison, France, November, 26-27, 2001: Editions Technip; 2002.

[5] Duret P, Dabadie JC, Lavy J, Allen J, Blundell D, Oscarsson J, et al. The air assisted direct injection elevate automotive engine combustion system. SAE Paper 2000-01-1899. 2000.

[6] Duret P, Venturi Sp. Automotive calibration of the IAPAC fluid dynamically controlled two-stroke combustion process. SAE Paper 960363. 1996.

[7] Mahmoudzadeh Andwari A, Azhar AA. Homogenous charge compression ignition (HCCI) technique: A review for application in two-stroke gasoline engines. Applied Mechanics and Materials. 2012;165:53-7.

[8] Mahmoudzadeh Andwari A, Aziz AA, Muhamad Said MF, Abdul Latiff Z. Controlled auto-ignition combustion in a two-stroke cycle engine using hot burned gases. Applied Mechanics and Materials. 2013;388:201-5.

[9] Asai M, Kurosaki T, Okada K. Analysis on fuel economy improvement and exhaust emission reduction in a two-stroke engine by using an exhaust valve. SAE Paper 951764. 1995. 
[10] Ghanaati A, Mat Darus IZ, Muhamad Said MF, Mahmoudzadeh Andwari A. A mean value model for estimation of laminar and turbulent flame speed in sparkignition engine. International Journal of Automotive and Mechanical Engineering. 2015;11:2224-34.

[11] Mahmoudzadeh Andwari A, Aziz AA, Said MFM, Latiff ZA. A converted twostroke cycle engine for compression ignition combustion. Applied Mechanics and Materials. 2014;663:331-5.

[12] Mahmoudzadeh Andwari A, Aziz AA, Said MFM, Latiff ZA, Ghanaati A. Influence of hot burned gas utilization on the exhaust emission characteristics of a controlled auto-ignition two-stroke cycle engine. International Journal of Automotive and Mechanical Engineering. 2015;11:2229-8649.

[13] Onishi S, Jo SH, Shoda K, Jo PD, Kato S. Active thermo-atmosphere combustion (atac)- a new combustion process for internal combustion engines. SAE Paper 790501.1979.

[14] Takei T, Iida N. Study on auto-ignition and combustion completion of n-butane in a two-stroke homogeneous charge compression ignition (HCCI) engine. 2002.

[15] Yu X, Wu H, Du Y, Tang Y, Liu L, Niu R. Research on cycle-by-cycle variations of an SI engine with hydrogen direct injection under lean burn conditions. Applied Thermal Engineering. 2016;109, Part A:569-81.

[16] Iodice P, Senatore A. A numerical-experimental approach to assess emission performance of new generation engines during the cold transient. nternational Journal of Automotive and Mechanical Engineering. 1988;13:3599-612.

[17] Rashid AK, Mansor MRA, Ghopa WAW, Harun Z, Mahmood WMFW. An experimental study of the performance and emissions of spark ignition gasoline engine. International Journal of Automotive and Mechanical Engineering. 2016;13:3540-54.

[18] Goto K, Iijima A, Yoshida K, Shoji H. Analysis of the Characteristics of HCCI Combustion and ATAC Combustion Using the Same Test Engine. 2004.

[19] Iida N, Yamasaki Y, Sato S, Kumano K, Kojima Y. Study on Auto-Ignition and Combustion Mechanism of HCCI Engine. SAE Paper 2004-32-0095. 2004.

[20] Nishida K, Sakuyama H, Kimijima T. Improvement of Fuel Economy Using a New Concept of Two-Stroke Gasoline Engine Applying Stratified-Charge AutoIgnition. 2009.

[21] Ozdor N, Dulger M, Sher E. Cyclic Variability in Spark Ignition Engines A Literature Survey. 1994.

[22] Zhang Y, Zhao H, Ojapah M, Cairns A. Experiment and analysis of a direct injection gasoline engine operating with 2-stroke and 4-stroke cycles of spark ignition and controlled auto-ignition combustion. SAE Technical Paper 2011-011774, 2011.

[23] K.R.Patil, S.S.Thipse. The effect of injection timing on the performance and emission of direct injection CI engine running on diethyl ether-diesel blends. International Journal of Automotive and Mechanical Engineering. 2016;13:377387.

[24] Math MC, M.S.Manjunath. Development and characterization of cerium oxide catalyst supported on ceramic honeycomb substrate to reduce emissions of spark ignition engine. Journal of Mechanical Engineering and Sciences. 2016;10:195667. 
[25] Iida N. Combustion analysis of methanol-fueled active thermo-atmosphere combustion (ATAC) engine using a spectroscopic observation. SAE Paper 940684. 1994.

[26] Visconti P, P.Primiceri, L.Strafella, Carlucci AP, Ficarella A. Morphological analysis of injected sprays of different bio-diesel fuels by using a common rail setup controlled by a programmable electronic system. International Journal of Automotive and Mechanical Engineering. 2017;14:3849-71.

[27] Mahmoudzadeh Andwari A, Abdul Aziz A, Muhamad Said MF, Abdul Latiff Z. An experimental study on the influence of EGR rate and fuel octane number on the combustion characteristics of a CAI two-stroke cycle engine. Applied Thermal Engineering. 2014;71:248-58.

[28] Mahmoudzadeh Andwari A, Aziz AA, Said MFM, Latiff ZA. Experimental investigation of the influence of internal and external EGR on the combustion characteristics of a controlled auto-ignition two-stroke cycle engine. Applied Energy. 2014;134:1-10.

[29] Nishi M, Kanehara M, Iida N. Assessment for innovative combustion on HCCI engine by controlling EGR ratio and engine speed. Applied Thermal Engineering. 2016;99:42-60.

[30] Zhao H, Ladommatos N. Engine combustion instrumentation and diagnostics. Warrendale, PA: Society of Automotive Engineers, 2001 842. 2001.

[31] Zhao H. HCCI and CAI engines for the automotive industry: Woodhead Pub.; 2007.

[32] Zhang Y, Zhao H, Ojapah M, Cairns A. CAI combustion of gasoline and its mixture with ethanol in a 2 -stroke poppet valve DI gasoline engine. Fuel. 2013;109:661-8.

[33] Zhang Y, Zhao H, Ojapah M, Cairns A. Effects of Injection Timing on CAI Operation in a 2/4-Stroke Switchable GDI Engine. SAE Int J Engines. 2011;5:6775.

[34] Said MFM, Aziz ABA, Latiff ZA, Mahmoudzadeh Andwari A, Soid SNM. Investigation of Cylinder Deactivation (CDA) Strategies on Part Load Conditions. SAE Technical Paper 2014-01-2549. 2014.

[35] Heywood JB. Internal combustion engine fundamentals: McGraw-Hill; 1988.

[36] Hairuddin A, Yusaf T, Wandel AP. Single-zone zero-dimensional model study for diesel-fuelled homogeneous charge compression ignition (HCCI) engines using Cantera. International Journal of Automotive and Mechanical Engineering. 2106;13:3309-28.

[37] Yao M, Zheng Z, Liu H. Progress and recent trends in homogeneous charge compression ignition (HCCI) engines. Progress in Energy and Combustion Science. 2009;35:398-437.

[38] Tsuchiya K, Hirano S, Okamura M, Gotoh T. Emission control of two-stroke motorcycle engines by the butterfly exhaust valve. SAE Paper 800973. 1980.

[39] Noguchi M, Tanaka Y, Tanaka T, Takeuchi Y. A study on gasoline engine combustion by observation of intermediate reactive products during combustion. SAE Paper 790840. 1979.

[40] Liu Y, Zhang F, Zhao Z, Dong Y, Ma F, Zhang S. Study on the synthetic scavenging model validation method of opposed-piston two-stroke diesel engine. Applied Thermal Engineering. 2016;104:184-92.

[41] Ishibashi Y, Asai M. A Low Pressure Pneumatic Direct Injection Two-Stroke Engine by Activated Radical Combustion Concept. SAE Paper 980757. 1998. 
[42] Nayak SK, Mishra PC. Emission from a dual fuel operated diesel engine fuelled with Calophyllum Inophyllum biodiesel and producer gas. International Journal of Automotive and Mechanical Engineering. 2017;14:3954-69.

[43] Blair GP. The basic design of two-stroke engines. Society of Automotive Engineers; 1990.

[44] Feneley AJ, Pesiridis A, Mahmoudzadeh Andwari A. Variable geometry turbocharger technologies for exhaust energy recovery and boosting - A Review. Renewable and Sustainable Energy Reviews. 2017;71:959-75.

[45] Mahmoudzadeh Andwari A, Pesiridis A, Esfahanian V, Salavati-Zadeh A, Karvountzis-Kontakiotis A, Muralidharan V. A comparative study of the effect of turbocompounding and orc waste heat recovery systems on the performance of a turbocharged heavy-duty diesel engine. Energies. 2017;10:1087.

[46] Mahmoudzadeh Andwari A, Pesiridis A, Karvountzis-Kontakiotis A, Esfahanian V. Hybrid electric vehicle performance with organic rankine cycle waste heat recovery system. Applied Sciences (Switzerland). 2017;7.

[47] Mahmoudzadeh Andwari A, Pesiridis A, Rajoo S, Martinez-Botas R, Esfahanian V. A review of battery electric vehicle technology and readiness levels. Renewable and Sustainable Energy Reviews. 2017;78:414-30.

[48] Salvi BL, Subramanian KA. Experimental investigation on effects of exhaust gas recirculation on flame kernel growth rate in a hydrogen fuelled spark ignition engine. Applied Thermal Engineering. 2016;107:48-54.

[49] Bhaskar K, Sendilvelan S, Muthu V, Aravindraj S. Performance and emission characteristics of compression ignition engine using methyl ester blends of jatropha and fish oil. Journal of Mechanical Engineering and Sciences. 2016;10:1994-2007.

[50] Ishibashi Y. Basic Understanding of activated radical combustion and its twostroke engine application and benefits. SAE Paper 2000-01-1836. 2000.

[51] Iijima A, Yoshida K, Shoji H. A comparative study of HCCI and ATAC combustion characteristics based on experimentation and simulations influence of the fuel octane number and internal egr on combustion. SAE Technical Paper 2005-01-3732, 2005. 